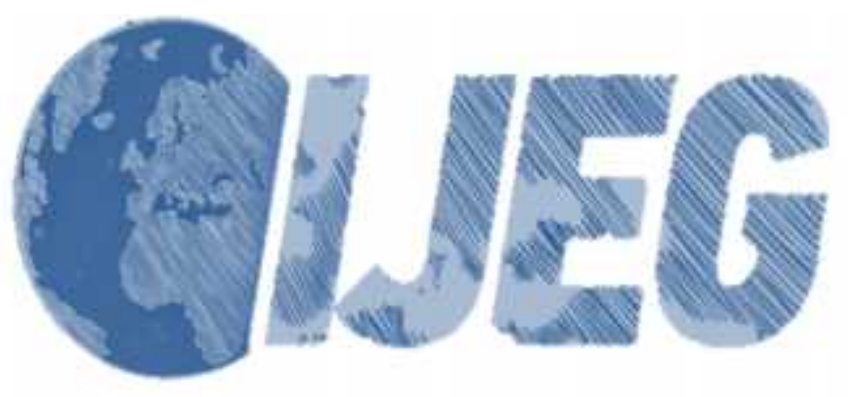

International Journal of Engineering and Geosciences (IJEG),

Vol; 2; Issue; 03, pp. 110-117, October, 2017, ISSN 2548-0960, Turkey,

DOI: $\underline{10.26833 / \text { ijeg.329717 }}$

\title{
EVALUATION OF ACCURACY OF DEMS OBTAINED FROM UAV-POINT CLOUDS FOR DIFFERENT TOPOGRAPHICAL AREAS
}

\author{
Akar, $\mathrm{A}^{*}$ \\ Erzincan University, Vocational School Land Registry and Cadastre, 24100 Erzincan, Turkey \\ (alperakar24@gmail.com)
}

ORCID: 0000-0003-4284-5928

*Corresponding Author, Received: 19/07/2017, Accepted: 21/08/2017

\begin{abstract}
The main objective of the study was to examine accuracies of DEMs (Digital Elevation Models) with different topographical structures generated by using the Unmanned Aerial Vehicle (UAV) point clouds. Two different terrains with flat and sloping topographical structures were selected for the study, and DEMs of these terrains were generated using eight interpolation techniques (Kriging, Natural Neighbor, Radial Basis Function Triangulation with Linear interpolation, Nearest Neighbor, Invers Distance to a Power, Local Polynomial and Minimum Curvature). The accuracies of DEMs were tested by calculating the statistic methods with the help of the control points obtained by land surveying techniques. At the end of the study, it was observed that in DEMs prepared for both flat (study area 1) and sloping (study area 2) terrains, Kriging interpolation method yields the best results as study area 1 and 2, respectively. In addition, the results were examined using Shapiro-Wilk and ANOVA: Friedman tests. After observing with the ShapiroWilk test that the data has a normal distribution, it was statistically determined through the parametric ANOVA: Friedman test that there is no difference between the variables.
\end{abstract}

Keywords: Digital Elevation Model; Unmanned Aerial Vehicles; Kriging; ANOVA. 


\section{INTRODUCTION}

Digital Elevation Models are topographical products which provide important information about the surface of the Earth and are used in many different applications such as modelling water flow (Jain and Singh, 2003), flood simulation and management (Honghai and Altinakar, 2011) and (Ramlal and Baban, 2008),terrain visualization and mapping (Spark and Williams, 1996). The accuracy of such applications depends on the accuracy of the produced Digital Elevation Model (Januchowski et al., 2010). Therefore, Digital Elevation Models with various accuracies can be prepared using different techniques depending on the desired accuracy. The most prominent techniques to prepare Digital Elevation Models are photogrammetric methods with stereo data (Hohle, 2009) and (Kraus, 2007), airborne laser scanning (Vosselman and Maas, 2010), radar interferometry (Arun, 2013) and land surveying (Wilson and Gallant, 2000).

Due to land surveys, traditional methods to prepare Digital Elevation Models have high cost and is time consuming (Uysal et al., 2015). The use of photogrammetric methods has therefore become very common due to the advantages they provide in terms of time, accuracy and costs when preparing Digital Elevation Models. One of these methods, LIDAR systems, has become a preferred method for Digital Elevation Model preparation thanks to its three dimensional information gathering capability, which is very effective for wide areas. However, the biggest disadvantage of these platforms is their high cost, especially in small areas of study (Remondino et al., 2011). Thus, there emerged a need for different techniques to produce data in applications in small study areas. In the last ten years, with the increase in the number of firms producing them, the costs of Unmanned Aerial Vehicles have decreased substantially, thus eliminating the problematic cost issue related to these platforms.

The use of these vehicles is becoming more and more common due to decreased costs of UAVs for different applications, eg. meteorological studies, natural disaster management, forest fire detection and control, agricultural product monitoring, mapping and threedimensional city and terrain modelling (Ruzgien , 2015), (Mesas-Carrascosa, 2014 ) and (Austin, 2010). It is believed that Unmanned Aerial Vehicles will be a significant alternative to the traditional mapping methods by allowing the production of maps at low costs while providing high spatial and temporal resolution (Colomina and Molina, 2014) and (Sauerbier and Eisenbeiss, 2010).

In scientific literature, it is accepted that the accuracy of the Digital Elevation Model depends on many factors such as topographic variance, sampling density, interpolation techniques and spatial resolution (Aguilar et al., 2005), (Gong et al., 2000) and (Kienzle, 2004). In the study conducted, using the point clouds obtained from UAV GatewingX100 images, the impact of the topographical variance and the different interpolation methods on the accuracy of the prepared Digital Elevation Model is investigated.

\subsection{Study area and data set}

Two different areas with distinct terrain structures were chosen to prepare Digital Elevation Models. Study area 1 (12 hectares) was selected in the area where KTU School of Divinity is located (latitude $40^{\circ} 59^{\prime} 06.60^{\prime \prime}$ and longitude $39^{\circ} 48^{\prime} 45.87^{\prime \prime}$ ) which has a fairly flat topographical structure without much elevation. Topographic elevation of study area 1 is between approximately $20 \mathrm{~m}$ and $40 \mathrm{~m}$. Study area 2 (40 hectares) was selected in the area where KTU Farabi hospital is located (latitude $40^{\circ} 59^{\prime} 32.97^{\prime \prime}$ and longitude $39^{\circ} 46^{\prime}$ 13.86 ") and it has a more sloping terrain. Topographic elevation in this area ranged from 80 to $170 \mathrm{~m}$ with slopes from $10^{\circ}$ to $58^{\circ}$, approximately (Figure 1).

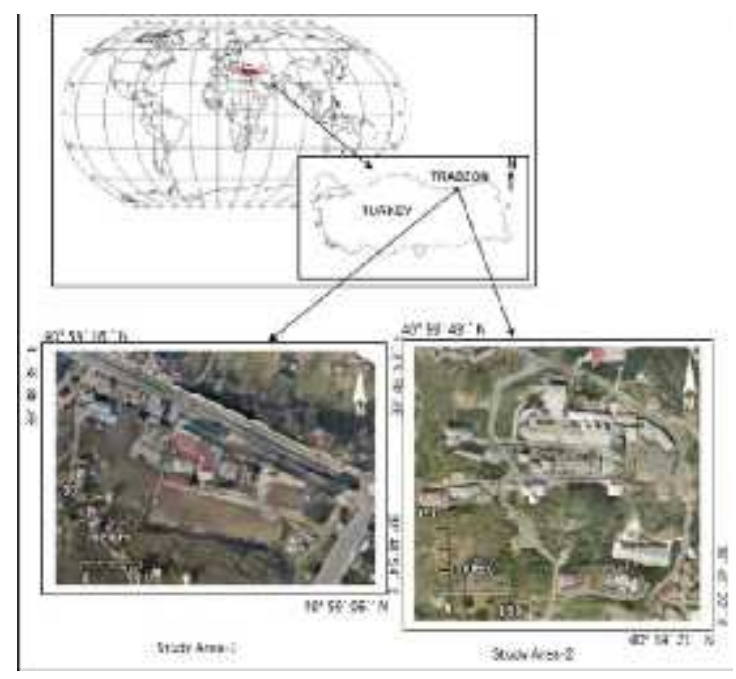

Figure 1. Study areas

\subsection{GATEWINGX100 UNMANNED AERIAL VEHICLE}

GatewingX100 Unmanned Aerial Vehicle (UAV) was produced by the firm Trimble to be used in photogrammetric mapping efforts. This vehicle consists of elements such as a Ricoh GR Digital IV digital camera, modem (2.4 Ghz), ground control station, launcher and electronic components known as ebox, like GPS, INS etc.

GatewingX100 UAV has a 1-meter wing span and weighs around 2 kilograms. This vehicle, which can capture very high spatial resolution images from 150200 meter average heights, can also take a photo in hot, cold, and lightly rainy weather conditions and in up to $60 \mathrm{~km} / \mathrm{h}$ winds. The camera used is very light and can capture very high quality images. Thanks to the ISO range it offers, it is able to generate high quality images in various light conditions. The camera used, with its technical specifications are shown in table 1 . 
Table 1. Technical specifications of Ricoh GR Digital IV digital camera

\begin{tabular}{|c|c|}
\hline $\begin{array}{l}\text { Image } \\
\text { Sensor }\end{array}$ & $\begin{array}{l}\text { 1/1.7-inch CCD (total pixels: } \\
\text { approx. } 10.40 \text { million pixels) }\end{array}$ \\
\hline $\begin{array}{l}\text { Focal } \\
\text { length }\end{array}$ & $\begin{array}{l}\mathrm{f}=6.0 \mathrm{~mm} \text { (equivalent to } 28 \mathrm{~mm} \\
\text { for } 35 \mathrm{~mm} \text { film cameras) }\end{array}$ \\
\hline F-aperture & $\begin{array}{l}\text { F1.9 - F9 (exposure control with } \\
\text { both aperture and ND filter when } \\
\text { F8.0-F11 displays in auto shooting } \\
\text { mode) F8.0-F11 displays in auto } \\
\text { shooting mode) }\end{array}$ \\
\hline $\begin{array}{l}\text { Shutter } \\
\text { Speed } * 1 \\
\text { Movie }\end{array}$ & $1 / 30-1 / 2000 \mathrm{sec}$ \\
\hline $\begin{array}{c}\text { ISO } \\
\text { Sensitivity } \\
\text { (Standard } \\
\text { Output } \\
\text { Sensitivity) }\end{array}$ & $\begin{array}{c}\text { AUTO, AUTO-HI, ISO80 - } \\
3200 \text { (1EV, 1/3EV, selectable steps) }\end{array}$ \\
\hline Weight & $\begin{array}{r}\text { Approx. } 219 \mathrm{~g} \text { (including the } \\
\text { supplied battery and SD memory }\end{array}$ \\
\hline $\begin{array}{c}\text { Operating } \\
\text { Temperature } \\
\text { Range }\end{array}$ & $0^{\circ} \mathrm{C}-40^{\circ} \mathrm{C}$ \\
\hline
\end{tabular}

\section{INTERPOLATION METHODS}

\subsection{Kriging}

Kriging developed by D.G. Krige is a geostatistical gridding interpolation method. Kriging is a very flexible method (Surfer guide 8.0, 2002). Making use of irregularly spaced data sets, the visually appealing maps are producted (Vohat et al., 2013). So, shape functions within the framework of meshless methods are constructed by using Kriging technique (Zhu et al., 2014). The principle of the Kriging technique is a variogram model, and this method uses weighted linear combinations (Ylimaz, 2009). The model of the method is presented here in below (Eq.1)

$$
\begin{aligned}
& \gamma\left(\mathbf{x}_{\mathrm{i}}, \mathrm{x}_{\mathrm{i}}\right)=\frac{1}{2} E\left[\mathbf{Z}\left(\mathrm{x}_{1}\right)-\mathbf{Z}\left(\mathbf{x}_{2}\right)^{2}\right]=\gamma(\mathbf{h}),\|\mathbf{h}\|= \\
& \left\|\mathbf{x}_{1}-\mathrm{x}_{2}\right\|, \mathbf{Z}_{\mathrm{p}}=\mu(\mathbf{P})+\boldsymbol{z}(\mathbf{P})
\end{aligned}
$$

Where $\boldsymbol{y}\left(\boldsymbol{x}_{i}, x_{i}\right)$ represents the semi variogram model giving a certain relation between any two nodes $\boldsymbol{x}_{\boldsymbol{i}}$ and $\boldsymbol{x}_{\boldsymbol{i}}, \boldsymbol{h}$ is a lag vector which indicates the Fuclidean distance between any two nodes. $\mu$ represents constant mean and $\varepsilon$ represents random errors. $\boldsymbol{Z}_{p}$ is the variable interest (Zhu et al., 2014) and (Yllmaz, 2009).

\subsection{Natural Neighbor}

The Natural Neighbour method bases on the average mean. The method uses the distance-dependent weights of reference points to the grid corner. The method classified the data on the reference points with irregular distribution, and by using the Triangular Irregular Network (TIN) functions it realizes interpolation process (Y1lmaz, 2009). The theory of the method is given in Eq.2.

$$
G(x, y)=\sum_{i=1}^{n} w_{i} f\left(x_{i}, y_{i}\right)
$$

Where $\boldsymbol{G}(\boldsymbol{x}, \boldsymbol{y})$ represents the natural neighbour estimation at $(\boldsymbol{x}, \boldsymbol{y}) . \boldsymbol{n}$ is the number of nearest neighbour used for interpolation. $\boldsymbol{f}\left(\boldsymbol{x}_{\boldsymbol{i}}, \boldsymbol{y}_{i}\right)$ is the observed value at $\left(\boldsymbol{x}_{\boldsymbol{t}}, \boldsymbol{y}_{i}\right)$ and $\boldsymbol{n}_{\boldsymbol{t}}$ is the weight function (Y1lmaz, 2009).

\subsection{Radial Basis Function}

Radial basis function (RBF) method has been used for their simplicity and ease of implementation in multivariate scattered data approximation. Furthermore RBF has been preferred as a method for the numerical solution of partial differential equations (Driscoll and Heryudono, 2007). The RBF interpolation method is explained as follows (Eq 3);

$s(x)=\sum_{i=1}^{n} \lambda_{i} \Phi\left(\| x-x_{i}\right)+p(x)$

Where interpolates the data are $\left(x_{1}, f_{1}\right), \ldots .,\left(x_{n}, f_{n}\right) . \quad n$ pair wise different points are $\boldsymbol{x}_{1}, \ldots \boldsymbol{x}_{n}$ and data $\boldsymbol{f}_{1} \ldots, \boldsymbol{f}_{n}, \boldsymbol{\lambda}_{i}$ is the coefficients. $\boldsymbol{i}=$

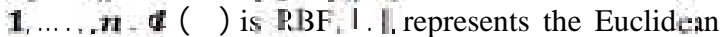
distance. $\boldsymbol{p}$ is from $\boldsymbol{n}_{\boldsymbol{w}}$, the space of polynomials of degree less than or equal to $m$ (Gutmann, 2001).

\subsection{Triangulation with Linear interpolation}

Triangulation with Linear Interpolation method uses triangles, which are created by drawing lines between data points by optimal Delaunay triangulation. The original points are connected in such a way that no triangle edges are intersected by other triangles. A sequential search then establishes the triangle in which each grid node is contained. Using the gradients of the selected triangle a value is interpolated for the grid node. The heights of the data points are preserved by interpolator, so the original data are used to define the triangles. Therefore, this method is an exact interpolator (Surfer guide 8.0, 2002).

\subsection{Nearest Neighbor}

The method is very simple to implement and is commonly used (Prasantha et al., 2009). The nearest neighbour assigns the value of the nearest point to each grid node. When data are already evenly spaced, this method is useful. Besides, when the data are nearly on a grid with only a few missing values, this method is effective for filling in the holes in the data (Surfer guide $8.0,2002)$. Sometimes with nearly complete grids of data, there are areas of missing data desired to exclude from the grid file. In this case, the Search Ellipse can be set to a certain value, so the areas of no data are assigned the blanking value in the grid file. By setting the search ellipse radii to values less than the distance between data 
values in file, the blanking value is assigned at all grid nodes where data values do not exist (Y1lmaz, 2009).

\subsection{Invers Distance to a Power}

Algorithm of Inverse Distance to a Power (IDP) method is based on a quite simple (Y1lmaz, 2009). It is a weighted average interpolator, and this interpolator can be either a smoothing or an exact. Data is weighted during interpolation so that the influence of one point relative to another declines with distance from the grid node, with Invers Distance to a Power (Surfer guide 8.0., 2002), (Vohat et al., 2013) and (Yang et al., 2004). The greater the weighting power, the less effect points far from the grid node has during interpolation. As the power increases, the grid node value approaches the value of the nearest point. For a smaller power, the weights are more evenly distributed among the neighboring data points (Eq.4) (Surfer guide 8.0., 2002).

$$
\begin{gathered}
\hat{\mathbf{z}}_{j}=\frac{\sum_{i=1}^{n} \frac{z_{i}}{h_{i j}^{\beta}}}{\sum_{i=1}^{n} \frac{1}{\frac{1}{\beta}}} \\
\boldsymbol{h}_{i j}=\sqrt{d_{i j}^{2}+\delta^{2}}
\end{gathered}
$$

Where $\boldsymbol{h}_{\boldsymbol{i}}$ is the effective separation distance between grid node. $\boldsymbol{j}$ and the neighbouring point $\boldsymbol{i}, \boldsymbol{z}_{\boldsymbol{j}}$ is the interpolated value for grid node $\boldsymbol{i} \cdot \mathbf{Z}_{i}$ are the neighbouring points. $\boldsymbol{d}_{i j}$ is the distance between the grid node $\boldsymbol{j}$ and the neighhouring point $\boldsymbol{i}$. $\boldsymbol{\beta}$ is the weighting power (the power parameter), and $\delta$ is the smoothing parameter (Y1lmaz, 2009).

\subsection{Polynomial Regression Method}

Polynomial regression method uses weighted least squares fit with data within grid nodes' search ellipse to assigns values to grid nodes (Surfer guide 8.0., 2002). The method does not predict unknown $\mathrm{Z}$ values, so it is not an interpolator (Yilmaz, 2009). The local least squares parameters are colnputed by minimizing the weighted sum of squared residuals as above (Eq.5);

$$
\begin{aligned}
& \left\{\left(x_{i}, y_{i}, z_{i}\right) \text { for } i=1,2,3 \ldots . . N\right\} \\
& \quad \text { Minimize } \sum_{i=1}^{N} u_{i}\left[F\left(x_{i}, y_{i}\right)-z_{i}\right]^{2}
\end{aligned}
$$

Where $\boldsymbol{x}_{i}, \boldsymbol{y}_{i}, \boldsymbol{z}_{i}$ represent known coordinates of datum $\boldsymbol{i} ; \boldsymbol{W}_{\boldsymbol{i}}$ is the weight for datum $\boldsymbol{i} ; \boldsymbol{F}\left(\boldsymbol{x}_{\boldsymbol{i}}, \boldsymbol{y}_{\boldsymbol{i}}\right)$ represents local polynomial (Surfer guide 8.0, 2002).

\subsection{Minimum Curvature}

The Minimum Surface Curvature method developed by (Briggs, 1974) is commonly used in earth sciences. According to the method, when the total curvature of a surface is minimized under the constraint that the surface honors the values in the gadded positions, the following Eq.6, which can be solved iteratively, apply (Cooke, 1993):

$$
\begin{aligned}
\frac{\partial^{+} P}{\partial x^{4}}+2 \frac{\partial^{4} \mathcal{P}}{\partial x^{2} \partial y^{2}}+\frac{\partial^{4} P}{\partial y^{4}} & =0 \\
0=P_{i+2 j}+P_{i j+2} & +P_{i-2 j+} P_{i j-2} \\
& +2\left(\boldsymbol{P}_{i+1, j+1}+\boldsymbol{P}_{i-1, j+1}\right. \\
& +\boldsymbol{P}_{\left.i+1,-1+\boldsymbol{P}_{i-1,-1}\right)} \\
& -\mathbf{8}\left(\boldsymbol{P}_{i+1, j}+\boldsymbol{P}_{i-1, j}\right. \\
& \left.+\boldsymbol{P}_{i j-1+} \boldsymbol{P}_{i, j+1}\right)+\mathbf{2 0} \boldsymbol{P}_{i, j}
\end{aligned}
$$

Gaged locations are obtained from the solution as their values are always honoured.

\subsection{Modified Shepard's Method}

The modified quadratic Shepard's method proposed by (Shepard, 1968) has been efficiently implemented for the multivariate interpolation of large scattered data sets. There are many advantages, such as numerical efficiency, good reproduction quality, stability and inherent parallelism (Lazzaro and Montefusco, 2002). The principle oftit the modified quadratic Shepard's method is given as kelow (Eq-7).

$$
\boldsymbol{F}(\boldsymbol{x})=\sum_{k=1}^{N} \overline{\boldsymbol{W}}_{k}(\boldsymbol{x}) \boldsymbol{R}_{k}(\boldsymbol{x})
$$

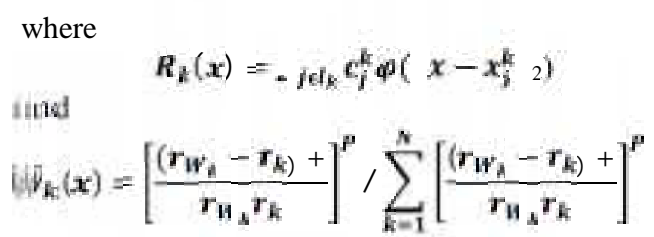

In Eq, 7, N represen's the number of scatter points in the set. $\boldsymbol{R}_{k}(\boldsymbol{x})$ represent the prescribed function values at the scatter points. $\bar{\nu}_{k}(\boldsymbol{x})$ are the weight functions assigned to each scatour point (Lazzaro and Montefusco, 2002).

\section{METHODOLOGY}

Methodology of this study was shown in Figure 2. Each phase of the study was explained step by step as the procedure of DEM production.

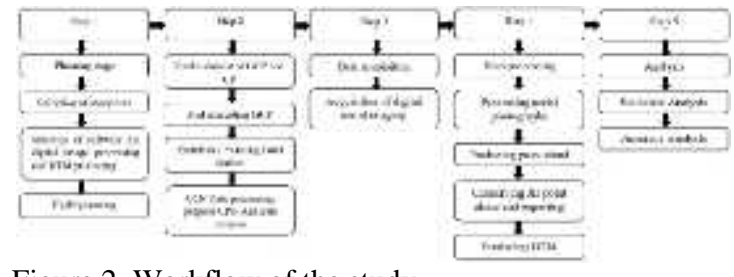

Figure 2. Workflow of the study

\subsection{Flight planning and taking of the photographs}

Before taking the photos, Ground Control Points (GCPs), which would be used to orient the photographs, were homogeneously selected and marked in ground. The coordinates of these GCPs were determined using Continuously Operating Reference Station-Turkey (CORS-TR) Global Positioning System (GPS) technique. There were 10 marked points for the first 
study area and 15 for the second. Pre-flight planning for the terrain was performed using Gatewing Quickfield software. Parameters such as overlap ratio, surface area to be captured, flight route, flight altitude, and determination of takeoff and landing points were all defined on the maps uploaded online to the ground control station and the software then prepared the flight plan based on this map.

This information was later uploaded from the ground control station to the Unmanned Aerial Vehicle in the field. To prevent any errors, the flight process was started after necessary controls were made (weather conditions in the study area, battery status of the aerial vehicle and its camera, the storage status of the memory card, flight controls, engine status of the vehicle and the working condition of the navigation, etc.). The flight process was completed by taking photographs throughout the determined route. By the end of the flight, 91 images overlapped $90 \%$, which have $5 \mathrm{~cm}$ GSD (Ground Sample Distance), were taken for the first study area and 160 images overlapped $90 \%$, which were $4 \mathrm{~cm}$ GSD, for the second.

\subsection{Data processing and DEM generation}

The main objective of the evaluation process was to produce the georeferenced three dimensional point cloud using the overlapped images (Siebert and Teizer., 2014). The interior orientation of the photographs was performed with Stretchout software. Afterwards, the exterior orientation process was started and performed with Photoscan software using the ground control points with known coordinates that were marked in the terrain. After the exterior orientation process the error rates in $x$ direction with $2.3 \mathrm{~cm}$, in $y$ direction with $2.3 \mathrm{~cm}$ and in $z$ direction with $1.9 \mathrm{~cm}$ were obtained for the first study area. The error rates for second study area were calculated in $\boldsymbol{x}$, $\boldsymbol{y}$ and $\mathbf{z}$ direction with $1 \mathrm{~cm}, 2 \mathrm{~cm}$ and 11 $\mathrm{cm}$, respectively. After the exterior orientation process, georeferenced three-dimensional dense point clouds and orthomosaics of the study areas were produced (Figure 3).

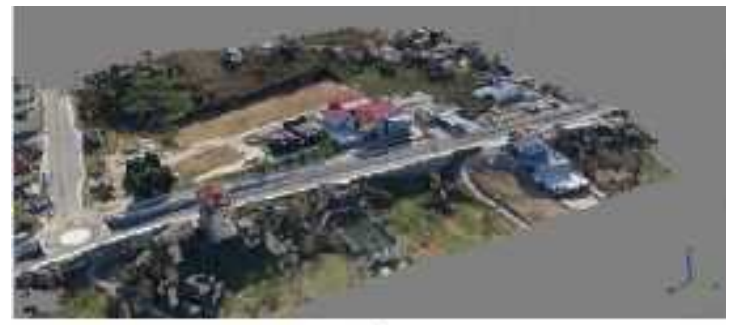

s)

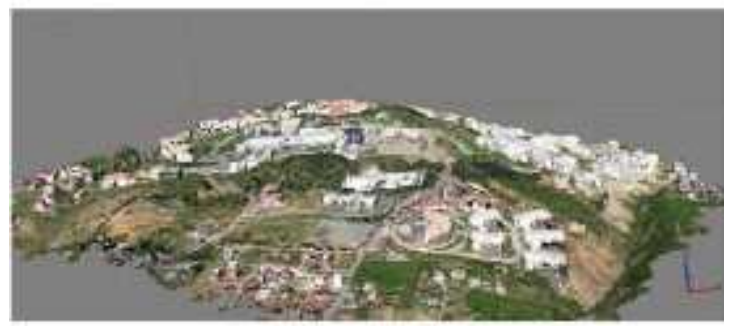

b)

Figure 3. Georeferenced three-dimensional dense point clouds a) Study area1 b) Study area2
Produced dense point clouds contained all details of the terrain (ground (soil, grass, road...) and non-ground (building, tree...) details). Because of this, for filtering the non-ground details the non-ground points were removed by using the Agisoft PhotoScan Professional software according their elevations. The dense point clouds were then exported as files with a "las" extension and this georeferenced three-dimensional point cloud was used to prepare the Digital Elevation Model with 1 meter grid size. Digital Elevation Models of both study areas were produced using different interpolation methods that are included in the Surfer 12 software.

\section{RESULT AND DISCUSSION}

Results of study were evaluated by using accuracy analysis and statistical tests. Firstly, accuracy analysis was conducted to compare the elevation values of test points obtained through land surveys in the study area with the elevation values obtained from the DEMs. In this study, the vertical accuracy of the produced DEMs were determined by means of field measurements at two study areas. 100 and 300 test points as reference were established in the study area 1 and 2 respectively (Figure 4).

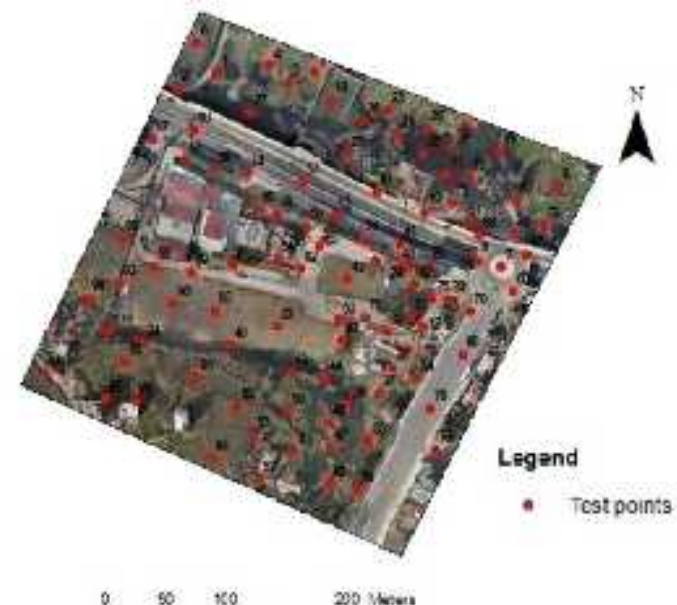

a)

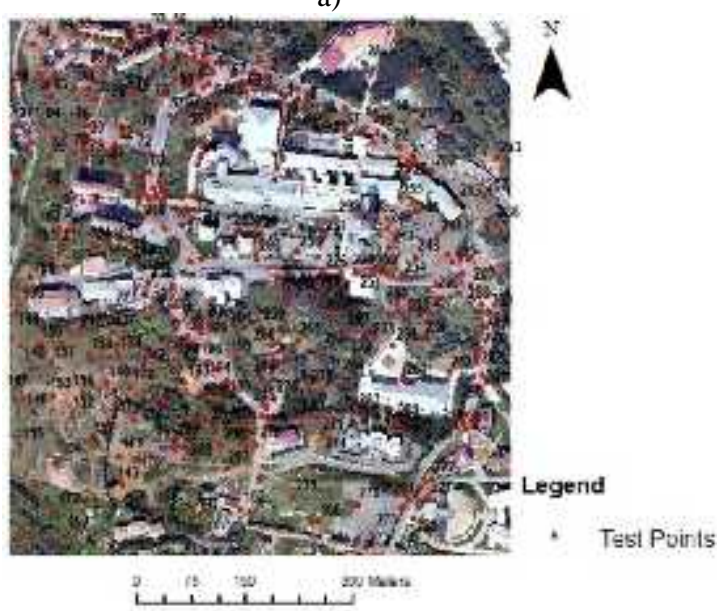

b) 
Figure 4. a) Test points for study area 1, b) Test points for study area 2

Horizontal and vertical positions of the test points were obtained with tacheometric measurements. The errors of the elevation values were then calculated by subtracting the elevation value of the corresponding test points from the elevation value of each point in the Digital Elevation Model. For each test site, the root mean square error (RMSE), standard deviation (SD) (residuals calculated by subtracting the measured elevation of a given benchmark from its elevation in the produced DEM), mean error (ME) and mean absolute error (MAE) were calculated between the measured elevations of the Total Station benchmarks (test points) and their elevations in the produced DEM. The calculated statistics are given in Figure 5, which also shows the minimum and maximum elevation errors of the benchmarks. The mathematical equations of the ME, MAE and RMSE are given as Eq.8, Eq.9, Eq.10 and Eq.11 respectively:

$$
\begin{aligned}
& \mathrm{ME}=\frac{1}{n} \sum_{i=1}^{n}\left(Z_{D E A}-Z_{R E F}\right) \\
& \mathrm{MAE}=\frac{1}{n} \sum_{i=1}^{n}\left(\left|Z_{D E \eta}-Z_{R E F}\right|\right) \\
& \mathrm{RMSE}=\sqrt{\frac{1}{n} \sum_{i=1}^{n}\left(Z_{D E A}-Z_{R E F}\right)^{2}} \\
& \mathrm{SD}=\sqrt{\frac{\sum_{i=1}^{n}\left(Z_{D E}-Z_{B E I}\right)}{n}}
\end{aligned}
$$

$\mathbf{Z}_{\text {DE }}$ in Eq. (8, 9, 10 and 11) refers to the elevation value of the corresponding points in the Digital Elevation Model, $\boldsymbol{Z}_{R E \text { I }}$ refers to the elevation value of the point as calculated by the tacheometric measurements in the field and $\boldsymbol{n}$ refers to the number of points.

RMSE, MAE, ME and SD were calculated for each interpolation method for study area 1 and 2 in Figure 5. As seen in Figure 5, minimum and maximum of RMSE were computed $11.4 \mathrm{~cm}-18.8 \mathrm{~cm}$ and $19.3 \mathrm{~cm}-27.3$ $\mathrm{cm}$ for study area 1 and 2, respectively. The calculated minimum and maximum values of SD range from $9 \mathrm{~cm}$ to $17.7 \mathrm{~cm}$ and from $20.7 \mathrm{~cm}$ to $31 \mathrm{~cm}$ for study area 1 and 2, respectively. The lowest $\mathrm{ME}$ value was calculated at $0.9 \mathrm{~cm}$ and $0.8 \mathrm{~cm}$ and the highest $\mathrm{ME}$ value was calculated at $4.4 \mathrm{~cm}$ and $3 \mathrm{~cm}$ for study area 1 and 2, respectively. Minimum and maximum of MAE were computed $9.9 \mathrm{~cm}-15.2 \mathrm{~cm}$ for study area 1 and 17 $\mathrm{cm}-24.8 \mathrm{~cm}$ for study area 2 .

Secondly, the obtained results were analyzed statistically. The Shapiro-Wilk test was applied to check whether the reference points that were used had a normal distribution. As a result of this test, it was observed that since the skewness and kurtosis values for the points of both study areas are between -1.5 and +1.5 (Tabachnick and Fidell 2013), the reference points have a normal distribution. Later, with this data that was determined to have a normal distribution, the ANOVA: Friedman test was used to measure the significance of the means that were obtained through different interpolation methods. Ho hypothesis claimed that "there is no difference between the variables." P-value was thus calculated at 0.17 for the first study area and 0.30 for the second. As p>0.05, Ho hypothesis was accepted at $95 \%$ confidence interval. Thus, it was statistically concluded that there was no difference between the variables.
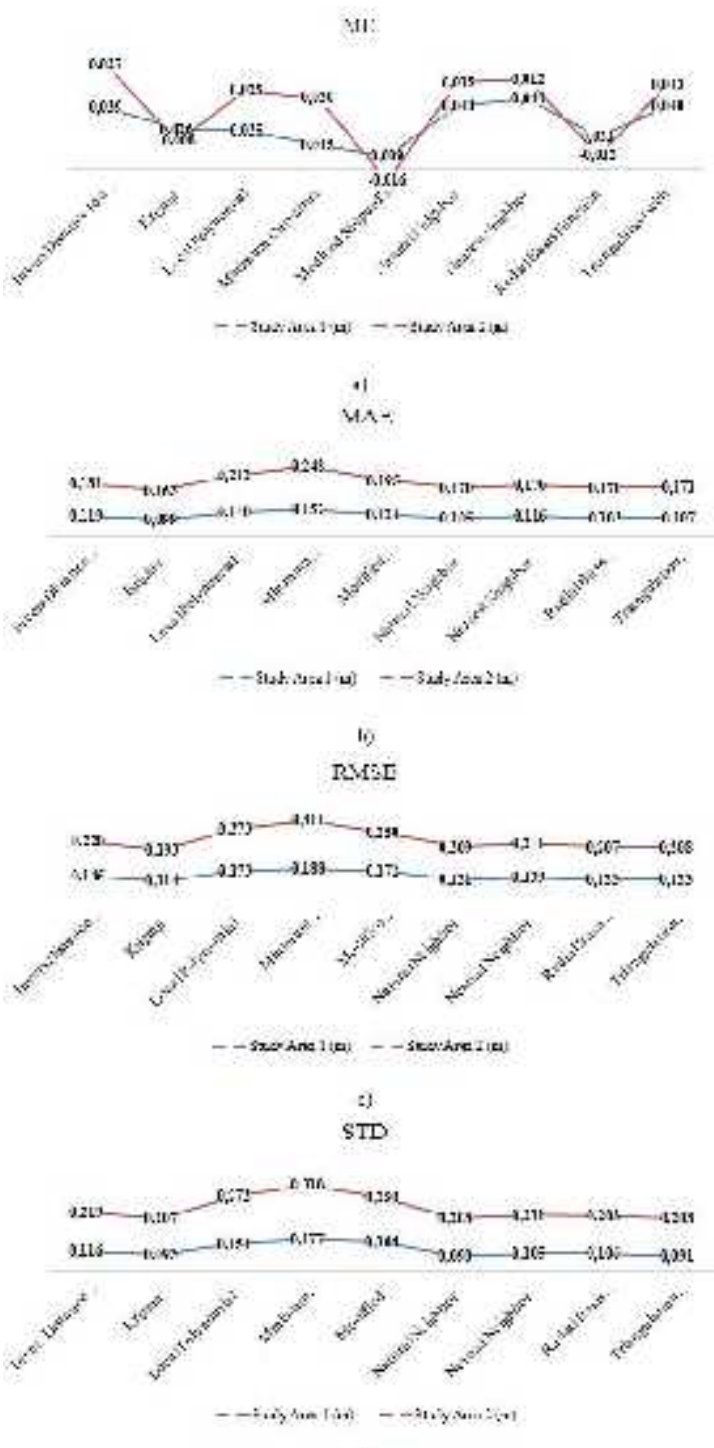

d)

Figure 5. The calculated statistics a) ME, b) MAE, c) RMSE, d)SD.

\section{CONCLUSION}

In this study, the objective was to determine the most appropriate interpolation method for Digital Elevation Model preparation in different terrains with various topographical structures, using UAV-point clouds. At the end of the study, in the DEMs produced for both flat and sloping terrains, RMSE, SD, ME and MAE were achieved for the Kriging interpolation method, generally. Therefore, it can be stated that the most accurate interpolation method to represent the terrain surfaces of the study areas is the Kriging method. In both study areas, Kriging interpolation method was followed by Natural Neighbour, Radial Basis Function and Triangulation with Linear Interpolation methods. 
The lowest accurate interpolation method is minimum curvature for each study areas.

In the event of missing or incorrect DEM data, the ability to obtain accurate new data using the appropriate interpolation methods may be time efficient and economically beneficial for the users. In addition, using UAV to gather these data would be highly beneficial for the users in terms of time, cost and accuracy.

\section{ACKNOWLEDGEMENTS}

UAV images in this study have been provided by the Department of Geomatics Engineering, Karadeniz Technical University.

\section{REFERENCES}

Jain, S.K. and Singh, V.P., 2003. Water Resources Systems Planning and Management.Fist ed. Elsevier, Amsterdam.

Honghai, Q.I. and Altinakar, M.S., 2011. A GIS-based decision support system for integrated flood management under uncertainty with two dimensional numerical simulations. Environmental Modelling and Software, 26 (6), 817-821.

Ramlal, B. and Baban, S., 2008. Developing a GIS based integrated approach to flood management in Trinidad. West Indies, Journal of Environmental Management, 88 (4), 1131-1140.

Spark, R.N. and Williams, P.F., 1996. Digital Terrain Models and the visualization of structural geology, Computer Methods in the Geosciences, 15, 421-446.

Januchowski, S.R., Pressey, R.L., Van Der Wal, J. and Edwards, A., 2010. Characterizing errors in digital elevation models and estimating the financial costs of accuracy. International Journal of Geographical Information Science, 24 (9), 1327-1347.

Hohle, J., 2009. DEM generation using a digital large format frame camera. Photogrammetric Engineering and Remote Sensing, 75 (1), 87-93.

Kraus, K., 2007. Photogrammetry - Geometry from Images and Laser Scans, Walter de Gruyter, Goettingen, Germany, p. 459.

Vosselman, G. and Maas, H.G., 2010. Airborne and Terrestrial Laser Scanning. CRC: Boca Raton, FL, USA, p. 318.

Arun, P.V., 2013. A comparative analysis of different DEM interpolation methods. Geodesy and Cartography, 39 (4), 171-177.

Wilson, J.P., Gallant, J.C., 2000. Secondary Topographic Attribute. in: Wilson, J.P.,Gallant, J.C. (Eds.), Terrain Analysis: Principles and Applications, John Wiley andSons., New York, pp. 87-131.

Uysal, M., Toprak, A.S. and Polat, N., 2015. DEM generation with UAV photogrammetry and accuracy analysis in Sahitler Hill, Measurement, 73, 539-543.
Remondino, F., Barazzetti, L., Nex, F., Scaioni, M. and Sarazzi, D., 2011. UAV Photogrammetry for mapping and 3D modelling current status and future perspectives. International Archives of Photogrammetry, Remote Sensing and Spatial Information Sciences, XXXVIII-1C22, pp. 25-31.

Ruzgien , B., Berteška, T., Gečyte, S., Jakubauskien , E. and Aksamitauskas, V.Č., 2015. The surface modelling based on UAV photogrammetry and qualitativeestimation. Measurement, 73, 619-627.

Mesas-Carrascosa, F.J., Notario-García, M.D., de Larriva, J.E.M., de la Orden, M.S. and Porras, A.G.F., 2014. Validation of measurements of land plot area using UAV imagery. International Journal of Applied Earth Observation and Geoinformation, 33, 270-279.

Austin, R., 2010. Unmanned Aircraft Systems: UAVs Design, Development and Deployment, John Wiley and Son Ltd. Publication, Hoboken, Chichester.

Colomina, I. and Molina, P., 2014. Unmanned aerial systems for photogrammetry and remote sensing: A review. ISPRS Journal of Photogrammetry and Remote Sensing, 92, 79-97.

Sauerbier, M. and Eisenbeiss, H., 2010. UAVs for the documentation of archaeological excavations. International Archives of Photogrammetry, Remote Sensing and Spatial Information Sciences, XXXVIII, Part 5, pp. 526-531.

Aguilar, F.J., Agüera, F., Aguilar, M.A. and Fernando, C., 2005. Effects of terrain morphology, sampling density, and interpolation methods on grid DEM accuracy. Photogrammetric Engineering and Remote Sensing, 71, (7), 805-816.

Gong, J., Li,. Z, Zhu, Q., Sui, H. and Zhou, Y., 2000. Effects of various factors on the accuracy of DEMs: an intensive experimental investigation. Photogrammetric Engineering and Remote Sensing, 66 (9), 1113-1117.

Kienzle, S., 2004. The effect of DEM raster resolution on first order, second order and compound terrain derivatives, Transactions in GIS, 8, (1), 83-111.

Surfer guide 8.0., 2002. Surfer 8.0 user's guide, Golden Software, Inc. Colorado, USA.

Vohat, P., Gupta, V., Bordoloi, T.K., Naswa, H., Singh, G. and Singh, M., 2013. Analysis of different interpolation methods for up hole data using Surfer software. 10th Biennial International Conference \& Exposition, 23-25 November, Kochi, Kerala, India.

Zhu, P., Zhang, L.W., Liew, K.M., 2014. Geometrically nonlinear thermomechanical analysis of moderately thick functionally graded plates using a local PetrovGalerkin approach with moving Kriging interpolation, Compos. Struct., 107, 298-314.

Yilmaz, I., 2009. A research on the accuracy of landform volumes determined using different 
interpolation methods. Scientific Research and Essay, 4 (11), 1248-1259.

Driscoll, T.A. and Heryudono, A., 2007. Adaptive residual subsampling methods for radial basis function interpolation and collocation problems. Comput Math Appl 53, 927-939.

Gutmann, H.M., 2001. A radial basis function method for global optimization. Journal of Global Optimization, 19 (3), 201-227.

Prasantha, H.S., Shashidhara, H.L. and Balasubramanya, M.K.N., 2009. Image Scaling Comparison Using Universal Image Quality Index, 2009 International Conference on Advances in Computing, Control, and Telecommunication Technologies, 28-29 December, Trivandrum, Kerala, India, pp.859-863.

Yang, C.S., Kao, S.P., Lee, F.B. and Hung, P.S., 2004. Twelve different interpolation methods: a case study of Surfer 8.0. In: Proceedings of ISPRS Congress 20, pp. 778-785.

Briggs, I.C., 1974. Machine contouring using minimum curvature, Geophysics, 39, 39-48.
Cooke, R., Mostaghimi, S. and Parker, J.C., 1993. Estimating oil spill characteristics from oil heads in scattered monitoring wells. Environmental Monitoring and Assessment, 28, 33-51.

Shepard, D., 1968. A two-dimensional interpolation for irregularly-spaced data function.

Lazzaro, D. and Montefusco, L.B., 2002. Radial basis functions for the multivariate interpolation of large scattered data sets. J. Comput. Appl. Math. 140, 521536.

Siebert, S. and Teizer, J., 2014. Mobile 3D mapping for surveying earthwork projects using an Unmanned Aerial Vehicle (UAV) system. Automation in Construction. 41, $1-14$.

Tabachnick, B.G. and Fidell, L.S., 2013. Using Multivariate Statistics, fifth ed.Pearson, Boston.

Copyright (c) International Journal of Engineering and Geosciences (IJEG). All rights reserved, including the making of copies unless permission is obtained from the copyright proprietors. 